\title{
A Utilização de Mapas Conceituais como Recurso Didático para a Construção e Inter- Relação de Conceitos
}

\author{
Using Concept Maps as a Teaching Resource \\ for Building and Interrelating Concepts
}

Valter Carabetta Júnior

PALAVRAS-CHAVE:

- Aprendizagem;

- Ensino;

- Conceitos.

KEYWORDS:

- Teaching;

- Learning;

- Concepts.
Recebido em: 13/02/2012

Reencaminhado em: 09/10/2012

Aprovado em: 20/05/2013

REVISTA BRASILEIRA DE EDUCAÇÃO MÉDICA

\section{ABSTRACT}

Concept maps, created by Novak and based on Ausubel's theory, can represent an important pedagogical strategy for students to learn about the construction of scientific concepts, helping them to integrate and correlate information, as well as assign meaning to what they are studying. In this article, we describe the work carried out with medical students using concept maps drawing on "generator themes" created in the discipline of Primary Health Care, based on the main health problems found in the local area. According to our studies, the use of maps can constitute an important methodological resource, supporting the alignment of adequate theoretical training to the interventions required in real life, as well as facilitating the appropriation of scientific concepts by students. 
"O fator mais importante influenciando a aprendizagem é aquilo que o aluno já sabe: determine isso e ensine-o de acordo".

(Ausubel; NovaK; Hanesian, ${ }^{1} 1980$ )

\section{INTRODUÇÃO}

É fato que uma das grandes dificuldades encontradas no processo ensino-aprendizagem, em todos os segmentos da escolaridade, refere-se à elaboração de conceitos científicos pelos alunos. Mesmo utilizados com frequência, tais conceitos, em geral, não são devidamente estruturados e internalizados. Embora muitas vezes ocorra uma correta verbalização do conceito, muitos estudantes não encontram argumentos para explicitá-lo quanto ao significado ou, então, não conseguem realizar sua inter-relação com outros conceitos, bem como utilizá-lo em situações reais.

Para muitos professores, o ato de conceituar se relaciona apenas com a verbalização de um termo ou objeto, o que se confunde, muitas vezes, com a ideia de definição. A tendência a utilizar a definição resulta de uma compreensão simplista da aprendizagem que, de certo modo, assume que não existe diferença entre expressão verbal e compreensão².

A definição se refere à caracterização do conceito, sendo este mais do que a verbalização das características de um termo ou objeto, vinculando-se a uma atividade psicológica complexa que consiste em abstrair as características essenciais de determinado termo ou objeto, estabelecendo discriminações, relações e representações para chegar a uma generalização. Nas generalizações, os conceitos possibilitam que as palavras representem classes inteiras de objetos, qualidades ou acontecimentos.

Sabemos que o conhecimento científico é uma construção da mente que ocorre pela confrontação com a realidade, sendo elaborado por um rompimento em relação às evidências anteriores. Dessa forma, deve-se considerar que os conceitos científicos são construídos ao longo da escolaridade e não podem ser considerados representações mentais isoladas, mas, sim, elementos organizados em algum tipo de todo estruturado, com complexos de inter-relações formando uma rede de significados que os articula entre si.

Os conceitos, como representações determinadas por signos linguísticos, são construídos pelo próprio indivíduo e, ao ordenarem as ocorrências do mundo real em categorias, moldam sua percepção sobre o mundo. Em cada momento da vida, o indivíduo dispõe de certa espécie de rede de conceitos interligados por relações de semelhança, contiguidade e subordinação, representando seu conhecimento acumulado sobre as coisas e o filtro através do qual será capaz de interpretar os fatos, eventos e situações com que se depara no mundo objetivo ${ }^{3}$.

Como um aspecto específico do funcionamento cognitivo, a construção de conceitos científicos é um dos assuntos mais relevantes no processo de ensino. Considerando que a efetivação da aprendizagem só acontece quando há apropriação conceitual, para que o professor possa conduzir o aluno nesse processo, torna-se necessário planejar uma prática pedagógica que possa garantir sua viabilização.

Devido ao estabelecimento de equivalências e ao agrupamento de ideias vinculadas à experiência em categorias definidas por atributos criteriais, os conceitos padronizam e simplificam o ambiente, permitindo a facilitação da aprendizagem receptiva, a solução de problemas e a comunicação ${ }^{4}$.

Assim, se pensarmos em uma abordagem construtivista de educação, a aprendizagem passa a ser entendida como uma construção realizada pelo próprio indivíduo por meio das relações que estabelece entre as informações que the são apresentadas, e entre elas com seus conhecimentos prévios. Nesse processo, para que a aprendizagem de conceitos seja efetiva, é necessária a conscientização do professor de que ele é o elemento responsável por conduzir o aluno na estruturação do conhecimento. E que, para isto, deve dispor de uma prática pedagógica que torne significativos os conteúdos trabalhados e que realize a interação entre o que vai ser aprendido com a estrutura cognitiva do indivíduo por um processo de assimilação entre antigos e novos significados, visando possibilitar a diferenciação cognitiva.

Se o modelo construtivista de ensino pressupõe que aprender de modo significativo é construir significados para as experiências; que compreender algo supõe estabelecer relações entre o que se está aprendendo com o que se sabe; e que toda aprendizagem depende de conhecimentos prévios ${ }^{5}$, podemos encontrar na obra de David Ausubel o pressuposto teórico necessário para almejar uma transformação na prática educativa, já que a aprendizagem significativa é a tese central de sua teoria cognitiva de aprendizagem.

De acordo com Ausubel ${ }^{1}$, a aprendizagem significativa é a ampliação da rede de conhecimentos do indivíduo que ocorre quando novos conceitos são integrados e reestruturados com os conceitos já existentes em sua estrutura cognitiva. Para que exista uma aprendizagem significativa, é necessário entender como ocorre o processo de transformação do conhecimento, bem como a importância que os processos mentais assumem nesse desenvolvimento.

Ausubel parte da consideração de que os indivíduos apresentam uma organização cognitiva interna baseada em conhecimentos conceituais cuja complexidade depende das relações hierárquicas que os conceitos estabelecem entre si, sendo a estrutura cognitiva compreendida como uma rede 
FIgURA 1

Estruturação Conceitual na Aprendizagem Significativa

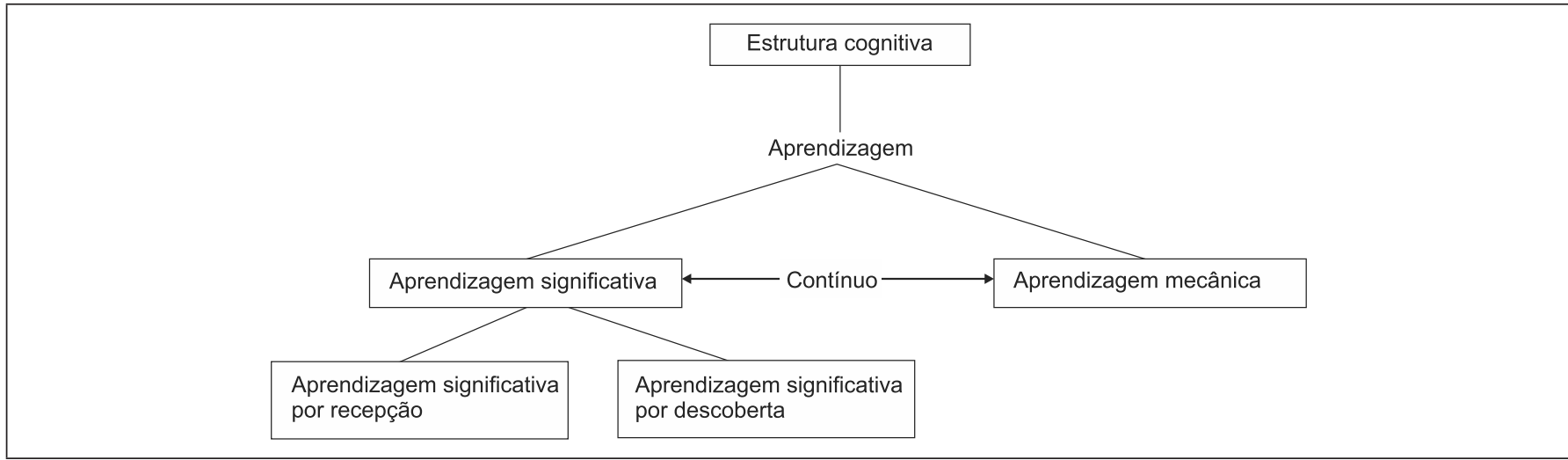

Fonte: Faria ${ }^{6} 1990$, p. 7.

de conceitos organizados hierarquicamente de acordo com o grau de abstração e de generalização. Propõe a existência de estágios sequenciais para a aquisição de conceitos, em que ocorrem: (a) análise discriminativa dos diferentes padrões de estímulos; (b) formulação de hipóteses com respeito aos elementos comuns abstraídos; (c) posterior testagem dessas hipóteses em situações específicas; (d) designação seletiva, a partir delas, de uma categoria geral ou conjunto de atributos comuns sob os quais todas as variantes possam se subordinar com êxito; (e) relação desse conjunto de atributos com ideias relevantes estabelecidas na estrutura cognitiva; (f) diferenciação do novo conceito dos conceitos relacionados previamente aprendidos; $(\mathrm{g})$ generalização dos atributos essenciais do novo conceito com todos os membros da classe; (h) representação do novo conteúdo categórico mediante uma linguagem simbólica, compatível com o uso convencional ${ }^{1}$ (p. 83).

A teoria da aprendizagem significativa considera ser mais fácil a apreensão dos aspectos diferenciados de um todo, anteriormente apreendido e mais inclusivo, do que formular o todo inclusivo por meio de partes diferenciadas anteriormente apreendidas.

Tal aprendizagem acontece quando uma nova informação se ancora (ancoragem), de maneira não arbitrária, a conhecimentos especificamente relevantes presentes na estrutura cognitiva do sujeito (subsunçores), podendo ser realizada de modo representacional (identificação e significação de símbolos com seus referentes); conceitual (representação abstrata das características relevantes do referente); proposicional (referente ao significado contido em determinada proposição).

De acordo com a teoria de Ausubel, os principais conceitos relativos à aprendizagem se estruturam da maneira indicada na Figura $1^{6}$ (p. 7).
Nesse processo, a linguagem assume papel de destaque no processo de estruturação conceitual, pois, atuando como elemento facilitador, possibilita: determinar e refletir sobre as operações mentais de níveis mais elevados e abstratos; assimilar por meio da definição do conceito e de seu contexto e facilitar a comunicação cognitiva interpessoal, enquanto permite a uniformidade cultural de conteúdos conceituais.

A essência do processo da aprendizagem significativa está no relacionamento não arbitrário e substantivo de ideias simbolicamente expressas com algum aspecto relevante da estrutura de conhecimento do sujeito, isto é, com algum conceito ou proposição que já lhe é significativo e adequado para interagir com a nova informação. É desta interação que emergem, para o aprendiz, os significados dos materiais potencialmente significativos. É também nesta interação que o conhecimento prévio se modifica pela aquisição de novos significados ${ }^{7}$.

Nesse contexto, o mapa conceitual, criado na década de 1970 por Joseph Novak $^{8}$ como técnica cognitiva para aprender de modo significativo, baseia-se na teoria ausubeliana e constitui uma estratégia pedagógica de grande relevância no ensino para a construção de conceitos científicos pelos alunos, ajudando-os a integrar e relacionar informações, atribuindo, assim, significado ao que estão estudando.

Em sua forma gráfica, os mapas conceituais correspondem a diagramas hierárquicos que mostram a organização e correspondência entre conceitos, que são apresentados por uma diferenciação progressiva (desdobramento de um conceito em outros que estão contidos) ou por uma reconciliação integrativa (relação de um conceito com outro aparentemente diferente). Ao dispor sob a forma gráfica de um mapa conceitual os conceitos conhecidos, relacionando esta noção inicial com outras também já conhecidas, estabelecendo uma hie- 
rarquia e/ou determinando propriedades, o aluno pode organizar seu conhecimento de maneira autônoma, retificando seu próprio raciocínio em função da construção do mapa. Os mapas conceituais demonstram ser uma ferramenta adequada porque possibilitam ao aluno (e ao professor também) desenvolver um processo cognitivo de aprendizagem em que ele próprio orienta a aquisição de novas informações porque elas estarão diretamente relacionadas com a estrutura de conhecimento prévio ${ }^{9}$ (p. 50).

Ontoria ${ }^{10}$ destaca três características próprias dos mapas conceituais: (a) hierarquização: os conceitos se encontram dispostos em ordem de importância, sendo que os mais inclusivos estão na parte superior e ligados a distintos níveis de concretude; (b) seleção: contém uma síntese gráfica dos aspectos mais importantes de um texto; (c) impacto visual: unidimensional - com apenas alguns conceitos dispostos de forma vertical; bidimensional - com conceitos dispostos vertical e horizontalmente; ou tridimensional - com conceitos e suas relações em três dimensões.

A utilização de mapas conceituais é uma técnica flexível para situações e finalidades diferentes, podendo ser usada para uma aula, uma unidade de estudo, um curso ou para o desenvolvimento de todo o programa educacional ${ }^{11}$.

Assim, este artigo descreve a dinâmica de utilização de mapas conceituais como estratégia pedagógica para possibiltar a apropriação de conceitos científicos pelos alunos.

\section{MÉTODO}

O trabalho foi realizado com 80 alunos do segundo semestre do curso de Medicina de uma universidade particular da cidade de São Paulo, tomando como base os "temas geradores" criados com os alunos na disciplina de Atenção Básica em Saúde a partir da constatação dos principais problemas de saúde da região onde se localiza a universidade. Tais "temas", ao longo do curso, convertem-se em projetos e trabalhos de pesquisa elaborados na disciplina de Metodologia Científica com o objetivo de controlar ou resolver os problemas de saúde relacionados.

No primeiro momento, para que os alunos pudessem entender a dinâmica de estruturação do mapa conceitual, escolhemos para a confecção do modelo um capítulo do livro de Biologia Celular adotado no curso. Após a leitura, sob a orientação do professor, o texto foi analisado e discutido e, então, utilizada a seguinte sequência didática:

— Identificação das ideias e conceitos mais importantes em estudo;

— Enumeração na lousa dos principais conceitos veiculados no texto;
- Avaliação e classificação dos conceitos enumerados por ordem decrescente de importância;

- Colocação de palavras-chave e formação de frases curtas com proposições adequadas com setas e/ou traços para ligar os conceitos enumerados;

- Identificação das ligações entre os diferentes conceitos que constituem o mapa;

- Leitura do mapa.

Na parceria estabelecida entre professor e alunos na confecção do mapa-modelo, surgiram diferentes perguntas - sobre estruturação e formato do mapa; relações conceituais que poderiam ser estabelecidas; ordenação dos conceitos e tipos de mapas que poderiam ser construídos —, o que resultou em uma interação dialógica profícua, tornando evidente o quanto os alunos estavam (re)significando conhecimentos, atribuindo significado à atividade proposta, realizando a construção de hipóteses e estabelecendo relações entre conceitos.

No segundo momento, escolhemos o tema gerador "desnutrição" para ser trabalhado. Porém, antes que os alunos lessem o texto escolhido - Desnutrição: consequências em longo prazo e efeitos da recuperação nutricional ${ }^{12}$ - e elaborassem o respectivo mapa conceitual, levantamos suas concepções prévias sobre o tema, escrevendo-as no quadro-negro. Então, com base nas palavras elencadas, pedimos que os grupos construíssem um mapa de conceitos com sentido para uma leitura sobre desnutrição.

Os mapas confeccionados apresentaram uma mesma configuração, pois os alunos procuraram seguir o modelo apresentado pelo professor. Demonstraram entender o pressuposto básico da estruturação de um mapa de conceitos, começando pelo mais geral e, a partir dele, desdobraram os outros conceitos, estabelecendo as relações entre eles numa sequência, ordenada, lógica e previsível, procurando deixar o mapa o mais autossuficiente possível.

Após a confecção e exposição de alguns mapas elaborados pelos alunos, a etapa seguinte consistiu no trabalho com o texto sobre desnutrição.

\section{RESULTADO E DISCUSSÃO}

Durante a construção dos mapas, o envolvimento dos alunos foi intenso, com troca de ideias sobre como começar a construção e como seria a estruturação do mapa. Nesse processo, o professor, como agente mediador do trabalho, acompanhou, em cada grupo, as discussões sobre o texto e quais conceitos nele veiculados estavam sendo considerados relevantes para a estruturação do mapa.

Na exposição dos trabalhos, os grupos fizeram uma análise comparativa da estruturação dos mapas quanto a dimen- 
FigURA 2

Mapas conceituais construídos de modo independente pelos alunos com o texto trabalhado

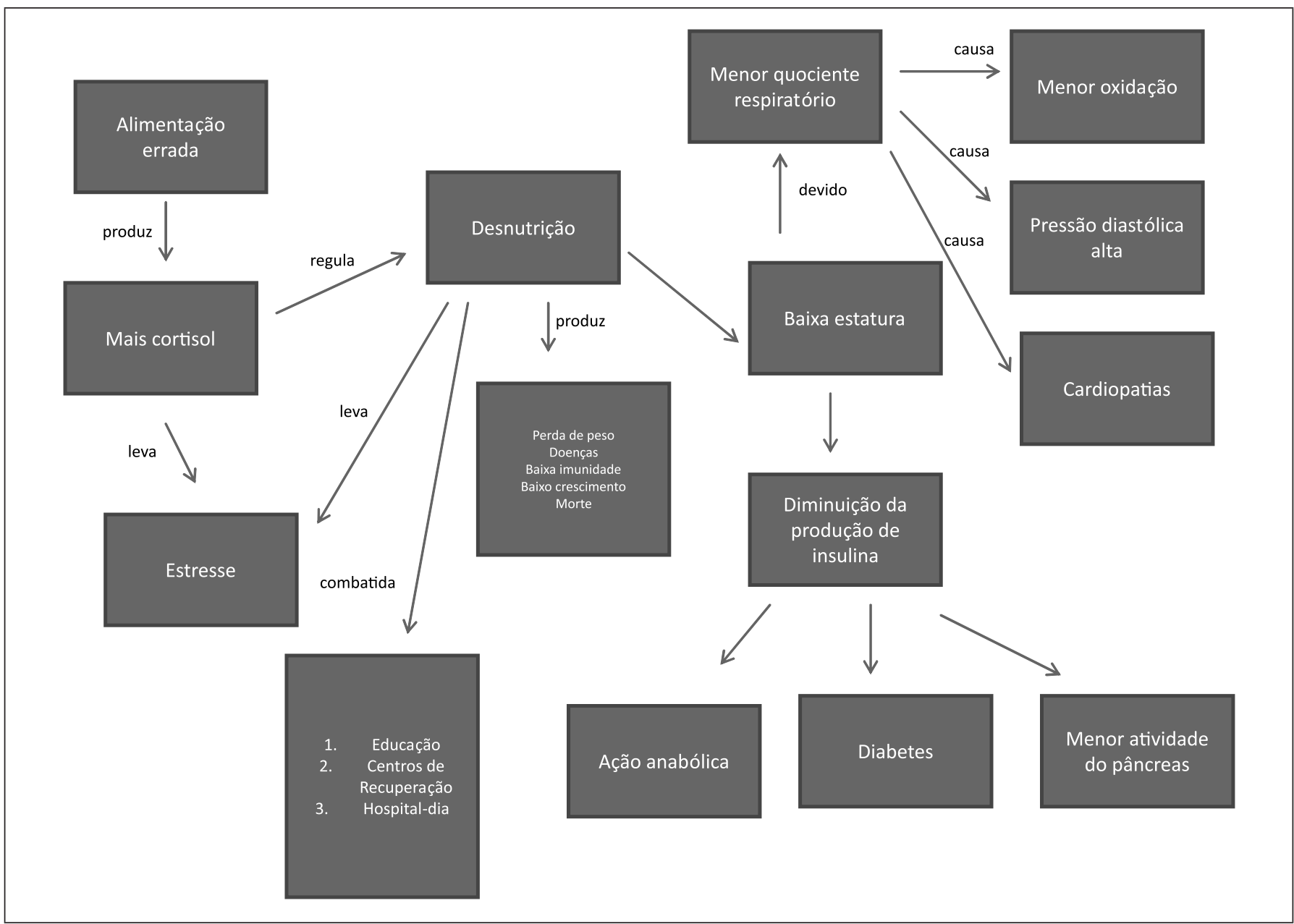

sionalidade, hierarquização conceitual e proposições de ligação, pois como diagrama de relações de significados o mapa conceitual não é autoexplicativo, necessitando da leitura de quem o fez.

Os mapas construídos pelos alunos sobre o texto trabalhado (Figura 2) têm configuração semelhante, com conceitos ordenados de maneira lógica, hierárquica e com palavras de ligação estabelecendo relações entre eles, permitindo, assim, interpretar o texto.

$\mathrm{Na}$ análise com o grupo dos mapas confeccionados, os alunos constataram que, embora o visual e as proposições de ligação dos mapas fossem diferentes, havia similaridade hierárquica na relação conceitual. Nas aulas seguintes foi possível observar avanços dos alunos nessa dinâmica, pois os diálogos aumentavam à medida que eles adquiriam maior co- nhecimento e segurança no processo, o que gerava reflexões sobre novas possibilidades de estruturação conceitual. Ao interpretarem a construção do mapa conceitual como atividade reflexiva e organizadora de conhecimentos, os alunos foram adquirindo maior condição de organizar, sistematizar e compreender suas próprias ações cognitivas.

\section{CONCLUSÃO}

Como no ensino superior é comum considerar que a intuição e a experiência são características importantes para a prática pedagógica, o ensino geralmente apresenta uma configuração tradicional, com aulas expositivas e cobrança de informações, sem a preocupação de levar o aluno à compreensão de conteúdos, produzindo apatia, problemas comportamentais e desinteresse pelas aulas ${ }^{13}$. 
Tal situação evidencia que a maioria dos professores universitários não considera importantes os conhecimentos pedagógicos e interpreta apenas o domínio dos conteúdos de sua área de conhecimento como requisito essencial para desenvolver um bom trabalho em sala de aula. A pragmática que orienta tal discurso é a concepção de que, durante a escolaridade básica, os alunos universitários já construíram os conceitos científicos estruturantes necessários para entender e relacionar os novos conhecimentos nas diferentes disciplinas e que, como adultos matriculados em cursos de graduação escolhidos e, portanto, em fase de profissionalização, sabem como estudar e têm a capacidade de aprender sozinhos.

A prioridade, no ensino superior, de reproduzir conhecimentos já elaborados ao invés de buscar e estruturar novos conhecimentos resulta de uma inércia no exercício da crítica epistemológica, e essa mesma inércia que privilegia comportamentos reprodutivistas em detrimento da busca da reconstrução metodológica contínua ${ }^{14}$.

No caso específico da escola de Medicina, área de nossa atuação docente, de acordo com a Resolução CNE/CES no ${ }^{4}$, de 07/11/2001, que institui as Diretrizes Curriculares Nacionais para o Curso de Graduação em Medicina, os artigos 9ำ e $12^{\circ}$ preconizam que o curso de graduação deve estar

[...] centrado no aluno como sujeito da aprendizagem e apoiado no professor como facilitador e mediador do processo ensino-aprendizagem [...], utilizando-se, para tanto, de [...] metodologias que privilegiem a participação ativa do aluno na construção do conhecimento e de [...] diferentes cenários de ensino-aprendizagem $[\ldots]^{15}$ (p. 38)

No entanto, como a maioria dos docentes que atua nas escolas médicas não teve formação pedagógica na graduação, há que se considerar que desconhecem teorias e práticas pedagógicas que podem subsidiar o processo ensino-aprendizagem para viabilizar um trabalho educacional que possibilite aos alunos a construção e/ou ampliação de conhecimentos e atribuição de significado ao que estão aprendendo.

Porém, se entendermos que o aluno é o construtor do seu conhecimento e o faz por meio de uma aprendizagem significativa, aprender de modo significativo consiste, então, em construir significados para as experiências; que compreender algo supõe estabelecer relações entre o que se está aprendendo e o que já se sabe e que toda aprendizagem depende de conhecimentos prévios, podemos considerar que tão importante quanto alimentar o conhecimento acadêmico é sua efetiva apropriação pelos alunos, e a tarefa fundamental do professor é elaborar estratégias de emergência de conhecimentos tácitos, resultantes tanto de atividades escolares quanto de vivências em ambientes extracurriculares.

Nesse sentido, por ordenarem e sequenciarem conhecimentos e conceitos de modo hierárquico em classes e subclasses, os mapas conceituais têm constituído um recurso metodológico relevante por se alinharem a uma formação teórica adequada às necessárias intervenções na realidade estudada $\mathrm{e}$ à apropriação de conceitos científicos pelos alunos, pois, embora sejam

[...] aparentemente simples e às vezes confundidos com esquemas ou diagramas organizacionais, mapas conceituais são instrumentos que podem levar a profundas modificações na maneira de ensinar, de avaliar e de aprender. [...] entram em choque com técnicas voltadas para aprendizagem mecânica. Utilizá-los em toda sua potencialidade implica atribuir novos significados aos conceitos de ensino, aprendizagem e avaliação $0^{16}$ (p. 10).

Se acreditarmos que a ação docente precisa de uma mudança que não envolva apenas o saber, mas também o saber fazer, não tanto o aprender, como o aprender a aprender ${ }^{17}$, faz-se necessária uma prática que incorpore abordagens metodológicas diferenciadas para tornar o ensino atraente e significativo.

Assim, se pretendemos um novo modelo de ensino superior em que o aluno seja sujeito e construtor de sua aprendizagem e que visualize a atividade dialógica como produtora de conhecimento, a proposta da utilização de mapas conceituais representa uma estratégia pedagógica que possibilita a criação de um ensino significativo, estabelecendo-se um novo tipo de pensamento operacional dependente das relações cognitivas e afetivas entre os participantes do processo de ensino-aprendizagem pela criação de espaços de constantes interlocuções qualitativas.

\section{REFERÊNCIAS}

1. Zabala A. A prática educativa. Porto Alegre: Artmed; 2006.

2. Oliveira MK. Algumas contribuições da psicologia cognitiva. Rev Ideias. 1992;32(4):276-84.

3. Moreira MA, Masini EFS. Aprendizagem significativa. São Paulo: Centauro; 2009.

4. Resnick LB. Mathematics and science learning: a new conception. Science. 1983;20:477-8.

5. Ausubel DP, Novak JD, Hanesian H. Psicologia da Educação. Rio de Janeiro: Interamericana; 1980.

6. Faria W. Aprendizagem e planejamento de ensino. São Paulo: Ática; 1990. 
7. Moreira MA, Caballero MC, Rodríguez ML (orgs.). Actas del Encuentro Internacional sobre el Aprendizaje Significativo. Burgos, España; 1997. [acesso em 10 jul 2011]. Disponível em http://www.if.ufrgs.br/ moreira/apsigsubport.pdf.

8. Novak JD. Uma teoria de educação. São Paulo: Pioneira; 1982.

9. Amoretti MSM. Protótipos e esteriótipos: aprendizagem de conceitos Mapas conceituais: experiência em Educação a Distância. Rev Inform Educ: teoria e prática. 2001;4(2):4955.

10. Ontoria A, Luque A, Gómez JPR. Aprender com mapas mentais: uma estratégia para pensar e estudar. São Paulo: Madras; 2004.

11. Amabis JM. Mapeamento de conceitos [online]. [acesso em 20 ago 2011]. Disponível em: http:/ /www.genoma.ib.usp. $\mathrm{br} /$ grupo/amabis/txt01.

12. Sawaya AL. Desnutrição: consequências em longo prazo e efeitos da recuperação nutricional. Estudos Avançados. 2006;20(58):147-58.

13. Krasilchik M, Araújo UF. Novos caminhos para a educação básica e superior. Com Ciência [periódico na internet]. 1 tela. [acesso em 10 nov. 2011]. Disponível em: ttp:/ / www. comciencia.br/comciencia / handler.php?section=8\&edica $\mathrm{o}=53 \& \mathrm{id}=670$.
14. Becker F. Construtivismo: apropriação pedagógica. In: Rosa DER, Souza VC, (orgs). Didática e práticas de ensino: interfaces com diferentes saberes e lugares formativos. Rio de Janeiro: Alternativa e DP \& A; 2006.

15. Brasil. Ministério da Educação. Conselho Nacional de Educação. Câmara de Educação Superior. Resolução CNE/ CES no 04 de 07 de novembro de 2001. Diretrizes Curriculares Nacionais do Curso de Graduação em Medicina. [acesso em maio 2011]. Disponível em: HTTP://portal. mec.gov.br/cne/arquivos/pdf/CES04.pdf.

16. Moreira MA. Aprendizagem significativa. Brasília: UnB; 1998.

17. Pelizzari A, Kriegl ML, Baron MP, Finck NTL, Dorocinski SI. Teoria da aprendizagem significativa segundo Ausubel. Revista PEC. 2002;2(1):37-42.

\section{CONFLITO DE INTERESSES}

Declarou não haver.

\section{ENDEREÇO PARA CORRESPONDÊNCIA}

Rua dos democratas, 445 - apto. 124

Vila Monte Alegre - São Paulo

CEP. 04305-000 SP

E-mail: vcarabetta@ig.com.br 